\title{
AO VENCEDOR AS BATATAS 30 ANOS: CRÍTICA DA CULTURA E PROCESSO SOCIAL Entrevista com Roberto Schwarz
}

\author{
por Lília Schwarcz e André Botelho
}

Há trinta anos, em 1977, era publicada a primeira edição de Ao vencedor as batatas, livro dedicado ao surgimento do romance no Brasil, composto por dois estudos substantivos, um sobre José de Alencar e outro sobre Machado de Assis, precedidos por um ensaio teórico-metodológico, hoje célebre, "As idéias fora do lugar" - ensaio que tem sido muito debatido, e mal compreendido, talvez por conta de seu título provocador. Com o livro, o cientista social e crítico literário Roberto Schwarz lançava um dos programas reconhecidamente mais consistentes, embora controverso, de análise da articulação sociológica entre forma literária e processo social no Brasil, cujo desenvolvimento envolve, até hoje, pelo menos dois outros livros: Um mestre na periferia do capitalismo: Machado de Assis (1997) e Duas meninas (1999). Neste programa crítico-sociológico o autor dá continuidade, também, a uma perspectiva de seu professor, Antonio Candido, que sempre apostou numa crítica literária que estabelecesse um diálogo tenso com as ciências sociais, pensadas de maneira mais ampla.

Além de uma abordagem inovadora sobre a configuração social que a particular resolução formal do realismo no Brasil revela, o programa crítico-sociológico de Schwarz perscruta as implicações estéticas e ideológicas do desenvolvimento desigual e combinado do capitalismo, bem como a ambivalência ideológico-moral entre ideário burguês e paternalismo inscrita na conduta dos grupos sociais engendrados na experiência brasileira daquele processo, e cujos efeitos atingem inclusive o desenho das instituições. A cópia de modelos exteriores passa a ser questão inevitável, sendo ela mesmo o que de mais interessante existe. Por outro lado, a existência da escravidão significaria um elemento fundamental a complicar a tradução das idéias liberais no país. Além disso, mais do que entender "traduções" era preciso pensar em "deslocamentos" e na viagem das idéias - no qüiproquó das idéias como diz 
Schwarz - que a aplicação desses conceitos, em regiões periféricas, acabava por provocar. Por esses e outros argumentos, a obra ganhou alcance e relevância que vão muito além das fronteiras disciplinares da crítica literária considerada em sua acepção especializada.

Roberto Schwarz nasceu em 1938, em Viena, Áustria. Formou-se em Ciências Sociais pela Universidade de São Paulo em 1960. Em 1963 tornou-se mestre em Teoria Literária e Literatura Comparada pela Universidade de Yale e, em 1976, doutor em Estudos Latino-Americanos pela Universidade de Paris III. Entre 1978 e 1992 foi professor de Teoria Literária na Unicamp. Publicou, entre outros trabalhos, A sereia e o desconfiado (1965), Ao vencedor as batatas: forma literária e processo social nos inicios do romance brasileiro (1977), O pai de família e outros estudos (1978), Que horas são? Ensaios (1987), Um mestre na periferia do capitalismo (1990), Misplaced ideas (1992), Duas meninas (1997) e Seqüências brasileiras (1999).

A seguir apresentamos a entrevista que Roberto Schwarz gentilmente nos concedeu em 24 de agosto de 2007, em sua casa em São Paulo, e que integrou as atividades elaboradas pelo Grupo de Trabalho "Pensamento Social no Brasil" para homenagear os trinta anos de Ao vencedor as batatas no âmbito do XXXI Encontro Anual da Anpocs realizado em outubro do mesmo ano - Encontro que comemorou também os trinta anos da Anpocs. ${ }^{1}$ $\mathrm{Na}$ entrevista, Roberto Schwarz fala sobre a formulação do livro, sua recepção ao longo desses anos e desenvolvimentos em trabalhos posteriores. Assim, entre outras questões cruciais, Schwarz revisa o debate sobre a dualidade inscrita na experiência social brasileira, seus efeitos na vida cultural e as diferentes respostas dadas a ela; reafirma o potencial heurístico da pesquisa da forma estética - não apenas dos "acertos estéticos", mas também dos "desacertos" - para a compreensão da vida social, bem como a importância da especificação do sentido histórico das formas e das idéias no trabalho do crítico da cultura.

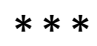

André Botelho - Ao vencedor as batatas ${ }^{2}$ trata do surgimento do romance no Brasil e do sentido por ele assumido entre nós, gostaríamos que o senhor nos falasse sobre o processo de formulação do livro.
Roberto Schwarz - O ponto de partida foi a impressão de que a ironia de Machado de Assis era muito brasileira. De modo geral, Machado era considerado o menos brasileiro dos escritores brasileiros. $\mathrm{O}$ maior, mas o menos brasileiro. Então, resolvi apostar na minha impressão contrária e estudar esse assunto, como tese de doutorado. Na época, a dialética estava em alta e um de seus focos - os focos da dialética mudam muito com o tempo era a ligação do mínimo ao abrangente, do mais singular, como o estilo ou a ironia de um autor, à estrutura de uma sociedade e, no limite, à história do mundo contemporâneo. Havia uma frase de Sartre que na época me impressionou muito. Sartre dizia que no andamento do estilo de um bom autor de alguma maneira está presente a história mundial. No Brasil, então, essa ordem de preocupações tem um interesse suplementar, que é o da desprovincianização, porque a gente aqui tem o hábito de ver as nossas coisas como sendo nossas e nada mais. Assim, havia um interesse em dissecar a ironia de Machado e mostrar que a escrita não é apenas uma solução pessoal, mas que ela pertence a uma história mais ampla, nacional, e que, no limite, o seu alcance pode ser mundial. Do ponto de vista da ambição crítica era um pouco por aí. Este caminho na época estava sendo aberto por Antonio Candido, no seu ensaio sobre a "Dialética da malandragem". ${ }^{3}$ Este ensaio faz muitas coisas, que precisam ser vistas em conjunto. Ele toma o movimento característico de um romance considerado menor, as Memórias de um sargento de milicias, descreve o seu andamento, desliga-o das intenções do romancista - estas no caso não têm importância, pois o alcance da forma é objetivo, sem conexão com os propósitos do autor -, mostra a pertinência nacional desse movimento, ou seja, do balanço da malandragem, interpreta as suas muitas implicações, para no final dizer: esse conjunto pode ser comparado, em espírito diferencial, ao romance do puritanismo norte-americano, A letra escarlate de $\mathrm{Ha}$ wthorne. Antonio Candido estava abrindo um caminho, procurando maneiras consistentes de incluir uma obra brasileira na discussão cultural contemporânea mais ampla, ou mundial.

Lilia Schwarcz - Ao mesmo tempo que brasileira, não é? Porque em "Dialética da malandragem" Antonio Candido tenta fazer uma espécie de arrazoado não só sobre o caráter nacional brasileiro, 
mas de que maneira a literatura poderia ser uma ponte relevante nesse sentido.

Roberto Schwarz - Isso. Antonio Candido buscava uma caracterização brasileira que por si mesma já se inscrevesse no debate contemporâneo, que é brasileiro, mas também internacional. É um percurso que ficou sendo um modelo. Voltando à ironia de Machado, o que me impressionou particularmente foi o vai e vem entre uma certa coisa um pouco empertigada, a linguagem ultracorreta, a finura analítica, muita citação clássica, e, de outro lado, algo que não era isso, que vinha das relações sociais características do país. Enfim, um tom de classe marcado, que entretanto não costumava ser visto como tal. É a arte de Machado. Procurei, então, caracterizar essa arte como sendo a combinação de um tom de classe cosmopolita aos desvios característicos da sociedade brasileira. Esse foi o ponto de partida. Eu sentia que a ironia de Machado se alimentava do vaivém entre oficialismo e desvio brasileiro da norma. Obviamente era uma retomada da "Dialética da malandragem" de Antonio Candido, no âmbito de Machado de Assis. Meu esforço foi inicialmente fixar a caracterização estilística desse vaivém, que viria a ser o tema de Um mestre na periferia do capitalismo muitos anos depois. ${ }^{4}$ Mas a questão estava presente no começo. Fixar uma fórmula estilística - essa oscilação - e, em seguida, tentar explicá-la em termos brasileiros. Aí tive a sorte de que meus professores estavam fazendo trabalhos que ajudavam a desenvolver essa perspectiva. Havia, de um lado, Fernando Henrique Cardoso, com Capitalismo e escravidão no Brasil meridional, ${ }^{5}$ que procurava mostrar que a escravidão - o desvio - não era o contrário do capitalismo - a norma internacional -, ao qual até certo momento ela foi útil. Portanto, a oposição entre capitalismo e escravidão não era o que parecia. Atrás da fachada liberal havia um mundo mental quase clandestino, sobretudo do ângulo europeu oficial. Ruminei bastante a tese de Fernando Henrique, mas faltava algo para chegar em Machado. Aí apareceu o livro de Maria Sylvia de Carvalho Franco. ${ }^{6}$

André Botelho - O senhor leu o livro ou a tese?

Roberto Schwarz - Li a tese.

André Botelho - Em 1964 mesmo?
Roberto Schwarz - Acho que li antes da defesa. Provavelmente não assimilei na primeira leitura. $\mathrm{O}$ fato é que foi ali por 1970, quando eu estava escrevendo "As idéias fora do lugar", 7 que ela fez diferença na minha cabeça. Na verdade, o que possibilitou fazer "As idéias fora do lugar" foi a combinação de Fernando Henrique e Maria Sylvia. Os dois não conversavam, mas os trabalhos deles eram involuntariamente complementares. Fernando Henrique mostrava que a escravidão era compatível com o capitalismo, que o capitalismo promovia a escravidão até um certo ponto, para depois deixar de promovê-la, claro. Com isso a escravidão deixava de ser um resíduo local e passava a estar inscrita no movimento geral da sociedade contemporânea. Tratava-se de fazer explodir o localismo. Analogamente, Maria Sylvia pegava o tema mais localista e confinado possível, que é o caipira, o homem livre e pobre, e mostrava que ele é complementar estruturalmente de um certo desenvolvimento do capitalismo, de um certo tipo de propriedade com objetivo econômico. Vendo com distância, essa era uma tendência da USP. Antonio Candido ia por aí em literatura, Fernando Henrique fazia isso em relação à charqueada no Sul, Maria Sylvia em relação aos processos-crime de Guaratinguetá. Era o projeto coletivo da dialética que estava em andamento, pautando as pesquisas. Para Maria Sylvia e Fernando Henrique, ele era diretamente marxista, ligado à leitura recente de $O$ capital. Para Antonio Candido, que era mais velho e tivera militância socialista anterior, e sabia muito sobre os partidos comunistas e a União Soviética, a relação era menos direta. Ele assumia muito do programa intelectual marxista, que entretanto cumpria com outros meios e sem terminologia canônica. Como a leitura dele era excepcionalmente grande e variada, adquirida com independência, ele acabou elaborando algo como um materialismo histórico paralelo. Com todas as diferenças, entretanto, há um fundo de época em comum a todos esses autores e a setores inteiros da USP. De certo modo, o básico do meu livro foi o casamento dessas três perspectivas, mais o estilo de análise de Adorno.

Lilia Schwarcz - Poderia nos falar mais sobre a introdução da perspectiva de Adorno?

Roberto Schwarz - Adorno desenvolveu uma idéia de forma paralela à de Antonio Candido, ou melhor, 
a de Candido é que é paralela à dele, que é anterior. Obviamente, são elaborações independentes. Enfim, em Adorno você tem a idéia de que ao fazer uma análise interna cerrada de uma obra de valor, você acaba descobrindo uma forma de organização que alude de maneira importante à história contemporânea. Esse é que é o ponto. É uma espécie de parti pris metodológico. Eu me entusiasmei muito com isso, de casar a análise estilística com a reflexão histórico-social. É o que Antonio Candido buscava fazer, especialmente em "Dialética da malandragem" e depois, logo em seguida, no ensaio sobre $O$ cortiço. ${ }^{8}$ São ensaios de alto nível, os mais complexos e inventivos da crítica brasileira. Antonio Candido, que é sempre muito discreto do ponto de vista metodológico, nunca falou das implicações da perspectiva dele. Já Adorno, que disputava a hegemonia teórica em toda a linha, no campo da filosofia da música, da teoria estética e da teoria da sociedade contemporânea, refletiu amplamente sobre a questão e mostrou a conexão desse tipo de análise com a dialética e com o marxismo. Em Adorno há realmente um programa de fazer descobertas sobre a sociedade contemporânea a partir da análise estética. Esse é um ponto muito importante. Em suma, o meu ponto de partida foi esse: uma análise da escrita, do estilo da segundo fase de Machado, mais uma tentativa de localizar os seus elementos no Brasil do tempo. Ao historicizar esses elementos, para romper a carapaça localista, acabei dando com as "Idéias fora do lugar", que nasceram do esforço de uma explicação estética. $\mathrm{O}$ ponto de partida da reflexão social no caso foi estético. Este ensaio teve um destino próprio, mais na área de ciências sociais, com um percurso diferente do resto do livro, que funcionou na área de Letras. Os ensaios foram lidos separadamente. Mas eles foram concebidos de maneira bem...

Lilia Schwarcz-Casada; articulada com o argumento geral?

Roberto Schwarz - Bem casada. Se você tomar o segundo ensaio, sobre a importância do romance de Alencar," ele retoma integralmente, agora no plano da história do romance, o esquema de "Idéias fora do lugar". Você tem uma forma literária européia que é trazida para o Brasil, onde é saturada de matéria local, o que vai produzir uma série de inconsistências e contradições não desejadas. Tento interpretar as contradições, de um lado, como defeitos estéticos, que fazem com que Senhora seja um livro limitado, mas, de outro lado, como reveladores do Brasil e como ponto de partida para um grande autor, que viria depois e seria Machado de Assis, que acaba inventando uma nova solução para a dificuldade. Assim, os defeitos são problemas para o autor seguinte, e vai se criando um fio interno, uma linhagem interna ao país. .

André Botelho - Um processo de acumulação estética?

Roberto Schwarz - Uma acumulação, exatamente. O autor seguinte, se por milagre for crítico e agudo como Machado, vê os pontos fracos e os supera, inventando combinações e soluções superiores. Isso é a retomada estrita das "Idéias fora do lugar" no plano da forma. A importação de uma forma foi criando impasses, assim como as idéias européias contemporâneas, combinando-se à escravidão e ao paternalismo, haviam criado por sua vez. Então, os impasses em Alencar são dessa mesma ordem e podem ser estudados desse ponto de vista.

Lília Schwarcz - Já era proposital então? Pergunto isso porque o senhor disse que a primeira idéia foi estudar Machado. Alencar surgia como contraponto?

Roberto Schwarz - De acordo com a tradição dialética, eu queria acompanhar a gênese da problemática do Machado. O que aconteceu é que de fato o plano inicial mudou um pouco, mas não no essencial. Vocês sabem que os primeiros romances de Machado são fracos. Daí, o meu plano inicial era a) "Idéias fora do lugar", b) Alencar e a importação da forma romanesca, c) um capítulo breve sobre os primeiros romances, e d) a grande fase. Tudo num volume só. Acontece que os romances do primeiro Machado praticamente não tinham sido estudados. Quando comecei a escavar um pouco mais, vi que ali havia um mundo, sem prejuízo de algo esteticamente diminuído. Então, o capítulo ligado a eles cresceu além do previsto. Para fins de tese, parei por ali mesmo, e as proporções do livro mudaram. O segundo volume ficou para depois. ${ }^{10}$ De fato, os romances da primeira fase são mais interessantes do que eu esperava. $\mathrm{O}$ processo de racionalização, ou de civilização do paternalismo, que está lá, o anseio de tornar o paternalismo me- 
nos destrutivo, nada disso eu tinha presente quando comecei a pesquisa. Queria procurar os temas da segunda fase na primeira, só por honra da firma. Aí, de repente, descobri que ali havia muito que estudar. São romances semi-ruins, mas ricos, tanto para a compreensão de Machado da segunda fase como para a compreensão do Brasil.

Lilia Schwarcz - Às vezes um mau romance é um bom documento. Baxandall sempre deixou clara essa perspectiva: "Uma má tela - como documento de época - é muito melhor do que uma ótima tela". ${ }^{11}$ Alencar era mau documento, nesse sentido?

Roberto Schwarz - Machado achou que dava para evitar pontos fracos de Alencar, o que é um modo de corrigir, mas a correção não saiu boa por sua vez. O ângulo que me interessou foi o do acerto estético, ou também do desacerto estético, os dois com substância social. Procuro explicar as razões pelas quais Alencar não dá certo, as razões pelas quais o primeiro Machado também não dá certo, e como isso vai criando um problema que o segundo Machado, de uma maneira realmente genial, soluciona. É claro que esse tipo de crítica depende de haver um bom escritor, um escritor que integre e supere os anteriores. Também neste sentido "Dialética da malandragem" é interessante, porque Antonio Candido mostra que a superação de impasses ou estreitezas, que faz a qualidade da prosa, o seu balanço, pode ocorrer de maneira meio inconsciente, rente ao sentimento da vida. É o trabalho artístico. O trabalho artístico é uma forma de pensamento fora do trabalho teórico. Manuel Antonio de Almeida não apontava para alturas intelectuais extraordinárias. Entretanto, ele solucionou um pedaço importante da problemática estética brasileira. Retomando a formulação de Baxandall, a diferença entre valor documentário e valor estético existe. Mas a qualidade artística não deixa de ser um "fait social", como diz Adorno, e a forma, mesmo a mais sutil, não deixa de ter valor de documento histórico a seu modo, se for bem entendida.

Lilia Schwarcz - Aliás, Manuel Antonio de Almeida também publicou de uma maneira sem pretensões; como fascículos de jornal. . .

Roberto Schwarz - Sem pretensão, o que faz parte da incrível graça dele.
Lilia Schwarcz - Só para ter claro isso: aparece na introdução e no tratamento de Alencar e de Machado de Assis uma questão de fundo que surge aqui também, e que se repete no segundo livro e no seu artigo "Nacional por subtração". ${ }^{12}$ Trata-se da questão da falsa crítica à cópia. O tema da cópia e da falsidade da cópia (e nós estávamos conversando - faz pouco tempo não só da literatura, mas do pensamento social brasileiro). Esse é um tema antigo em nossa história do pensamento social. Silvio Romero, por exemplo, acusou sua geração anterior de copiar, mas ele mesmo foi ultrapassado pela idéia da cópia.

Roberto Schwary - E copiou freneticamente.

Lília Schwarcz - No momento da gestação de Ao vencedor as batatas esse tipo de debate sobre a questão da cópia foi importante?

Roberto Schwarz - A palavra cópia se tornou importante com Derrida. Na altura em que eu escrevi isso, o que eu tinha na cabeça era o deslocamento das ideologias.

Lília Schwarcz - É o que você chama de nossas "esquisitices nacionais"?

Roberto Schwarz - Aí tem um ponto que se presta a mal-entendidos. Esse ensaio não é uma crítica da cópia das idéias. É uma tentativa de explicar por que as idéias copiadas, ou melhor, por que as idéias importadas dão entre nós a impressão de postiças.

Lilia Schwarcそ - No fundo são as mais verdadeiras.

Roberto Schwarz - Tratava-se de uma explicação estrutural de por que nos países periféricos as idéias adiantadas dão a impressão de postiças ou copiadas. O que não quer dizer que você possa não copiar. Não está disponível em um país como o Brasil não copiar. Só para um ignorante voluntário. . .

Lília Schwarcz - Essa opção não se coloca, não é verdade?

Roberto Schwarz - É, não se coloca. Seria absurdo. O que é preciso é ter juízo na maneira de encarar as idéias contemporâneas e saber o que cabe e o que não cabe, o preço que se paga para adotá-las. Num 
país periférico, o que está ao alcance é ser judicioso na relação com o ultramoderno. Mas não está à disposição não se ligar com ele, sob pena de regressão. Os tempos mudaram muito, e isso hoje parece evidente. Mas até a década de 1970, o desejo de uma cultura nacional "autêntica", antiimperialista, sem mistura e sem dívida com o estrangeiro, era forte.

André Botelho - É curioso como, a meu ver - não só a meu ver -, sua tese foi a princípio pouco compreendida. Como o senhor pensa a leitura que Maria Sylvia de Carvalho Franco fez do seu ensaio ${ }^{13}$

Lilia Schwarcz - Inspiradora e...

André Botelho - Aliás, em Sentimento da dialética, ${ }^{14}$ Paulo Arantes refere-se à interpretação de Maria Sylvia do seu ensaio como um equívoco, ou um mal-entendido, na medida em que a sugestão de que "As idéias fora do lugar" estava repondo uma dualidade, de modo algum procede - e creio que ele tenha razão. É curioso, por outro lado, como Maria Sylvia filia o seu ensaio a Fernando Henrique Cardoso, à teoria da dependência. ${ }^{15}$ Corretamente, pelo que estamos percebendo.

Roberto Schwarz - Todos pertencíamos a uma corrente mais ou menos comum.

André Botelho - Mas há diferenças substantivas entre o seu trabalho e o dela, não?

Lilia Schwarcz - Por exemplo, na idéia de "favor". Maria Sylvia reduziria o debate só à questão do capitalismo e à inserção do país como país marginal na lógica... E na sua interpretação que aparece aqui da idéia de favor ela surge como um modelo maior. Não é isso? Que não ficaria subsumido só...

Roberto Schwarz - Aqui há muitas perguntas. O destino do ensaio foi muito determinado pelo título, "As idéias fora do lugar". Muita gente que leu quis pôr as idéias no lugar. O que aliás mostra a que ponto o sentimento de que as idéias estão fora do lugar no Brasil é difundido. As pessoas gostariam de não sofrer desse deslocamento das idéias, que é expressão da ordem mundial. Mas não há como...
Lília Schwarcz - Às vezes os alunos de ciências sociais acham que o título do seu livro é As idéias fora do lugar!

Roberto Schwarz - A seu modo, o título é uma piada. Procura nomear e sublinhar uma impressão, mas não para dizer que ela está certa. Que as idéias modernas estejam fora do lugar no Brasil é o maior lugar comum do pensamento conservador brasileiro, e eu não ia repeti-lo. Desde a primeira constituição liberal, as pessoas diziam: "Isso não serve para o Brasil. São idéias estrangeiras. Tudo só no papel". Enfim, eu não ia escrever para dizer que as idéias liberais estavam fora do lugar num país com escravidão. O que tentei explicar foi por que razões, que são de classe, ligadas à iniqüidade social do país, as pessoas sentem que elas, as idéias novas, estão fora do lugar. É a explicação - marxista - de uma impressão. Nesse sentido, é um trabalho de crítico literário. Você tem uma impressão de superfície e o trabalho do crítico é explicar essa impressão.

Lília Schwarcz - Muito próximo da "Dialética da malandragem", não é?

Roberto Schwarz. - Sem dúvida. Voltando a Maria Sylvia e à objeção que ela me faz, de dualista: o dualismo não se suprime por um ato de vontade, ele é um dado geral do capitalismo em toda parte, é a sociedade cindida. Agora, se você é um espírito dialético, não pára na dualidade e trata de revê-la dentro de um movimento mais amplo e de fundo. Entretanto, se você recusa a dualidade como ponto de partida, você não faz análise dialética. Aliás, não só dialética, vira tudo um mingau indiferenciado. Mas voltemos à questão do favor. Maria Sylvia, no trabalho dela, explica muito bem como o caipira, o homem pobre, depende do favor de um proprietário e que o proprietário, participando do âmbito do capital, tem uma margem de manobra que o homem pobre não tem. O proprietário pode se comportar em relação a seu dependente seja como um senhor à maneira antiga, com o qual há uma relação de reciprocidade moral, seja como um burguês moderno que não deve nada a ninguém, cada um por si. Isso colocava o dependente em uma situação de grande desvantagem, porque ele nunca sabia se ia ser tratado como uma pessoa com a qual há reciprocidade, há obrigações, ou como 
um estranho, que pode ser posto para fora, pode ser expulso da propriedade. Se estou bem lembrado, este é o núcleo da contribuição dela. Note que a relação entre dependente e propriedade rural, que existe - o latifúndio cria os pobres sem direitos -, é um lugar comum da observação social brasileira. Em 1855, esse tema já estava formulado num livrinho de Lacerda Werneck. Depois, Nabuco discutiu a questão amplamente no Abolicionismo, com grande categoria. ${ }^{16}$ As reflexões de Caio Prado sobre o aspecto inorgânico da sociedade brasileira em boa parte também tratam disso. ${ }^{17}$ Então, a contribuição de Maria Sylvia não estava aí Ela retomou o tema a propósito dos processos-crime de Guaratinguetá, e avançou na análise da relação, em cujos meandros morais e em cujo enquadramento histórico-mundial entrou. Foi esse o passo à frente, se não me engano, à parte a exposição de um universo muito interessante. Ao redescobrir essas relações no sistema de personagens de Machado, situado na corte, acabei trazendo para a capital o esquema que ela havia analisado na zona rural.

Lília Schwarcz - No caso dela a análise limitava-se, em seu alcance, ao ambiente rural.

Roberto Schwarz - A questão reaparecia em posição central para o país, com o grau de abstração e a envergadura próprias ao grande romancista. Até aí penso que não há maiores diferenças, e o trabalho dela obviamente ajudou muito o meu. A diferença considerável vai se dever ao objeto. O romance de Machado, pelo estilo, abrirá uma frente que no material de Maria Sylvia não podia existir. A inflexão setecentista da prosa, calcada em mestres franceses e ingleses, expõe a experiência brasileira aos padrões gerais da ordem burguesa. Com isso, a temática que Maria Sylvia estudou em versão rural é medida pelo metro da civilização dita adiantada, e mais - aí entra a grande imparcialidade machadiana - ela não será só medida, como vai medir ela também. Aí há uma viravolta sensacional, propriamente uma façanha intelectual-artística. Vocês notem que só porque estava lidando com Machado é que pude entrar por essa seara. A passividade do Brasil diante dos padrões gerais da ordem burguesa é grande, até hoje. Até segunda ordem, o Brasil não é a medida da ordem burguesa, o Brasil é um efeito dela. Então vem um grande autor e diz: "Bem, vamos desenvolver uma escrita em que um âmbito se reflita no outro e fica para o leitor a tarefa de situar-se e de dizer quem está certo - provavelmente nenhum dos dois."

Lília Schwarcz - É possível dizer, então, que há um deslocamento do argumento da "originalidade da cópia". Ou seja, na análise de Maria Sylvia não existiria possibilidade alguma de pensar que aqui teríamos algum modelo original.

Roberto Schwarz - São questões determinadas pelo objeto. Ela estava com um objeto passivo - nem o agregado nem o proprietário rural iam dizer o que pensavam do mundo contemporâneo -, ao passo que eu lidava com uma obra que é um caso quase único no Brasil: um escritor que, sem ser regressivo, teve coragem de duvidar do padrão europeu. Isso os contemporâneos de Machado, mesmo os admiradores, sentiam só como uma espécie de ceticismo ou niilismo descabido. Silvio Romero dizia: "Lá vem ele com essas fumaças de misticismo idiota, um desfibrado que não acredita em nada". Machado teve a ousadia e a isenção extraordinárias de dizer: "Bem, nossos modelos e juízes também são parte interessada e tampouco escapam do ridículo". Há parcialidade interesseira e ridículo dos dois lados. Assim, o objeto empurra o crítico para ângulos diferentes. Eu não tenderia a ver divergências de fundo com Maria Sylvia, antes uma diferença de objetos. No essencial houve colaboração, a querela é secundária. Mas naturalmente é preciso perguntar o que ela acha. [risos]

André Botelho - Agora, considerando do ponto de vista teórico-metodológico "As idéias fora do lugar" também parece ter sido mal compreendido, o que ocorre já na leitura de Maria Sylvia de Carvalho Franco, na medida em que o argumento dela parece ser: "as idéias não podem estar fora do lugar porque elas cumprem uma função social". Mas o que o seu ensaio está formulando é: "Sim, a despeito disso, no entanto, elas permanecem deslocadas porque há a historicidade própria da sociedade brasileira; idéias não funcionam com variáveis sistêmicas interligadas e intercambiáveis de modo independente dos seus contextos históricos".

Roberto Schwarz - Você tem toda razão. Maria Sylvia me atribui a idéia de que as idéias não têm função no Brasil. Isso nunca me ocorreu. Aliás, procuro 
explicar minuciosamente quais as funções que têm. Entre parênteses, essa opinião dela é também de Alfredo Bosi, que me faz a mesma crítica.

André Botelho - De Bosi, e também de Carlos Nelson Coutinho, que aponta os interesses de classe como mediação entre a importação de idéias européias e a realidade brasileira. ${ }^{18}$

Roberto Schwary-As idéias produzem efeito de deslocamento, sem prejuízo de terem função. Esses não são aspectos incompatíveis. Elas têm função e dão a impressão de estarem fora do lugar - ao mesmo tempo. Num momento de hegemonia liberal ascendente, a escravidão é um problema, mesmo que dê dinheiro e esteja adaptada localmente. Os deslocamentos são efeitos locais da ordem mundial.

Lilia Schwarcz - Elas também produzem significados sociais, não é mesmo?

Roberto Schwarz - É.

André Botelho - Ainda no plano da recepção, eu gostaria de perguntar sobre Franco Moretti, já que ele vem utilizando bastante os seus trabalhos. Como na idéia de "mercados narrativos" que ele vem formulando no Atlas do romance europeu e também em artigos publicados na New Left, como o senhor vê essa recepção? ${ }^{19}$

Roberto Schwarz - Moretti é um autor extremamente inventivo e está tentando criar modelos de história literária para a globalização. Ele se interessou pelo meu ensaio sobre Alencar, porque trata da viagem das formas e da problemática que essa viagem pode criar. Para ele veio a calhar. Nesse aspecto, há um pormenor talvez interessante. John Gledson, que preparou uma edição inglesa de ensaios meus, resolveu incluir esse estudo sobre Alencar. $^{20}$ Achei um absurdo. "Mas, para quê você quer publicar esse ensaio? Ninguém vai ler. Senhora é um romance de segunda categoria, não é traduzido, não interessa a ninguém, publique outra coisa". O John insistiu, disse que eu estava enganado e que o esquema da viagem da forma interessa muito. Daquele livro com certeza é o ensaio que mais chamou atenção; Gledson é que viu certo.
Lilia Schwarcz - É mesmo. Mais uma vez o livro "menor", digamos assim é que interessa mais para pensar a forma e não o particular?

Roberto Schwarz - Eu havia visto a imigração da forma como um problema da acumulação literária brasileira, ou da atualização cultural de uma excolônia. Moretti, que está estudando esse tipo de migração de um modo geral e noutra escala, interessou-se pelo ensaio. É que esse tema da viagem das formas é um tema importante.

Lilia Schwarcz - Que viaja mais.

Roberto Schwarz - É isso, um tema que viaja bem [risos]. Viaja melhor do que a análise da prosa, por exemplo.

Lília Schwarcz - Viaja mais porque permite uma leitura mais universal (digamos assim) e menos pautada na própria experiência brasileira?

Roberto Schwarz - Moretti começou fazendo, entre outras coisas, uma espécie de comparatismo europeu, centrado na viagem das formas e dos gêneros pela Europa. A tragédia espanhola, a tragédia shakespeareana e o Trauerspiel alemão; o romance espanhol, inglês, alemão e francês etc. Um sistema, que é europeu, com especificações nacionais. Isso na Europa funciona muito bem, porque, como a Europa toda se movimenta do feudalismo para o capitalismo, ainda que em ritmos diferentes, as mesmas coisas acontecem com sentidos relativamente comparáveis nos diferentes lugares, um pouco antes e um pouco depois. Lukács, aliás, já havia visto assim a evolução do romance: o romance francês antes de 1848, o romance russo antes de 1905, e as próprias revoluções, são etapas que guardam correspondência. Enfim, esse movimento funciona bem sob o fundo homogêneo da transição do feudalismo para o capitalismo. Quando se vai para o mundo das ex-colônias, não há o paralelo, porque a colonização é algo novo, de iniciativa européia, mas que não repete a ordenação social da Europa. Então, a viagem das formas começa a criar o samba do crioulo doido, porque elas se "aplicam" a uma realidade de outra ordem, que é o que aconteceu no Brasil. Ando fuçando histórias literárias de países de que não sei nada. Tem-se esse mesmo tipo de problemática na literatura japone- 
sa, em fins do século XIX, na literatura coreana, na literatura hindu, na literatura turca, para não falar da russa, que é mais familiar. Há uma problemática da periferia e das ex-colônias. Quando aparecer alguém que saiba português, coreano, hindu e tal, ele vai enxergar e criar um objeto novo, que existe e está esperando formulação. Ou também, quando tudo estiver traduzido para o inglês, vai ser possível a comparação. Vai aparecer um conjunto disparatado, mas consistente à sua maneira, que é o correlato da situação de periferia. Voltando a Moretti, que começou fazendo comparatismo europeu, ele agora está atrás de esquemas adequados à globalização. Ele se interessou por esse meu trabalho, que, pelo contrário, se ligava a questões de afirmação nacional, e que entretanto pode se integrar ao esquema dele. O curso das coisas não é linear.

Lilia Schwarcz - Ainda sobre esse tema da recepção da sua obra para outras áreas do conhecimento. $\mathrm{O}$ diálogo que Rodrigo Naves em $A$ forma difícil estabelece entre o seu trabalho e uma reflexão sobre a história da arte no Brasil, particularmente a análise sobre Debret, seria também um outro deslocamento das idéias? ${ }^{21}$

Roberto Schwarz- Tudo isso sai da idéia de formação de Antonio Candido: seu livro, que manda estudar a retomada da tradição ocidental nas circunstâncias brasileiras, bem como o processo de acumulação e diferenciação que vai criando o que ele chama de sistema literário. ${ }^{22} \mathrm{O}$ processo existe no campo literário, e também noutros campos, do cinema, da pintura etc., com as diferenças de cada caso. Rodrigo está atrás disso no campo da pintura. O esquema é muito produtivo: um período de acumulação, que permite a maturação de uma problemática própria e uma criação mais independente, mais equilibrada, menos exposta à influência sem critério, à macaqueação direta.

André Botelho - É a sua explicação sobre a relação entre forma estética e formação social.

Lilia Schwarcz - Apesar de que com Rodrigo, no caso do Debret, se entendo bem, o que ele mostra é que a forma caminha mais difícil por conta da incompatibilidade entre o modelo e a realidade; já no caso do modelo neoclássico, a escravidão é o limite para pensar...
Roberto Schwarz - É o objeto dele. Quer dizer, Debret não é um grande artista, salvo melhor juízo. Ele seria uma espécie de Alencar, dentro desse esquema. Debret teve que desistir em certa medida Rodrigo Naves mostra isso - da forma neoclássica para poder desenhar o que ele via aqui. Mas não se tornou um grande artista, o objetivo no caso aliás não seria esse. Mas poderia vir outro pintor depois, que aprofundasse os seus resultados, ou suas renúncias. Mas poderia também não aparecer. Porque não precisa aparecer, não é? Machado de Assis não precisava ter aparecido. Se ele não aparecesse, ou ficasse nos romances da primeira fase, todo o romance do século XIX brasileiro não passaria de médio. Com exceção de Memórias de um sargento de milicias, que é um momento brilhante, sem ser máximo. Aí aparece o milagre de um escritor que sintetiza os antecessores e dá um passo. Esse escritor sempre pode não acontecer. Aparece numa arte, noutra não.

André Botelho - Gostaria de ouvi-lo sobre sua análise da relação entre forma estética e formação social, análise que também aparece fortemente nas suas leituras da Formação da literatura brasileira de Antonio Candido, ${ }^{23}$ em especial sua discussão sobre correspondências e desencontros entre processos formativos distintos, mas mutuamente referidos no caso, entre o bem-sucedido processo de formação da literatura com Machado de Assis e o da sociedade brasileira, marcada por um tipo de máformação.

Roberto Schwarz - Esse tipo de análise pressupõe alguma acumulação prévia, um acervo de observações compatíveis sobre algumas estruturas artísticas e a estrutura social. Os impasses da estrutura social existem sob forma de defasagem histórica, de brutalidade pura e simples, de iniqüidade, impotência, ridículo, disparate e outras incongruências, e naturalmente contradição. A gente vai vivendo com o que está aí. Alguém vai pedir consistência ao país? Não está na ordem do dia, salvo em momentos de crise profunda. Agora, é da natureza do trabalho estético que se veja tudo de todos os ângulos e busque alguma integração. Faz parte da intensificação estética e da criação de consistência que todos os ângulos se reflitam uns nos outros e que se tirem as conseqüências do que se formou; que se avance, que se encontre uma forma superior, capaz de 
integração. A obra de arte, nesse sentido, é um espelho mais consistente, que vai onde o cotidiano não chega. A rotação da prosa machadiana, que combina o mundo abafado do paternalismo às formulações lapidares - de cunho setecentista - sobre o egoísmo burguês, dá nitidez a desajustes que normalmente se perdem na trivialidade do dia-a-dia, se é que chegam a se esboçar. Tudo se torna problemático em novo grau. É claro que a sociedade não dá o passo equivalente. A sociedade fica na gelatina mesmo. Nesse sentido, as obras consistentes anunciam passos que podem não ser dados. A sua problemática tem fundamento real, mas no ambiente favorável da imaginação a hélice gira muito mais, é muito mais livre. No poema tudo se reflete em tudo, o que a seu modo é uma radicalização, uma forma de conseqüência. Mas grandes observadores da vida social eventualmente podem fazer isso também. Nos grandes livros isso acontece, tudo se reflete em tudo, e a realidade quase se estetiza. Acontece em Nabuco, Gilberto Freyre, para não falar em Marx.

Lília Schwarcz - Essa é uma perspectiva da crítica literária muito específica da escola paulista. Mais especificamente da Universidade de São Paulo?

Roberto Scbwarz - É sobretudo de Antonio Candido e dos que aprenderam com ele.

Lília Schwarcz - Essa idéia de que a produção literária tem algo a dizer sobre a sociedade, seus valores, suas identidades. . .

Roberto Schwarz - É uma coisa que vai na contracorrente da teoria literária metropolitana. Antonio Candido deu esse passo no momento em que na França estava jogando fora - mesmo a esquerda - o lado da referência. Foi realmente um passo de grande independência da parte dele. Mas a USP estava em veia de independência na época. Houve passos análogos em sociologia, em filosofia, em história, e talvez noutras disciplinas que não acompanhei.

Lília Schwarcz - Muita independência mesmo, porque essa discussão ficou caricaturada entre os formalistas e os historicistas. Nesse momento o assim chamado "historicismo" era quase um mal, não acha?
Roberto Schwarz - A particularidade de Antonio Candido é que ele é formalista e historicista ao mesmo tempo.

André Botelho - Como o senhor diz: uma crítica que articula "filiação de textos e fidelidade à contextos". ${ }^{24}$

Roberto Schwarz-Além de incluir a análise formal. A onda do estruturalismo foi grande, mas o trabalho que ficou - sem alardes de método - foi o de Antonio Candido. Sem os cacoetes de escola, são as análises mais estruturais e minuciosas, bem como inventivas, do período. O programa do estruturalismo histórico ficou parado no ar. Sartre diz no prefácio da Crítica da razão dialética: "A ressurreição do marxismo depende de se conseguir um estruturalismo histórico". No momento em que LéviStrauss estava afirmando que estrutura não tem nada a ver com história, Sartre concluía que o marxismo só ressuscita se operar essa ligação. Em Antonio Candido ela está feita. É preciso dizer que quem realizou abundantemente esse programa, bastante antes, foram Adorno, Benjamin e Lukács, este quando não era stalinista. Noutras palavras, há uma franja marxista que levou isso a cabo, se explicou a respeito, mas não se impôs em grande escala. É um fato significativo, que ainda precisa ser explicado. Às vezes penso que o marxismo vai acabar se impondo como construção intelectual quando ele já não tiver nenhuma relevância prática. Se você olhar - é a minha opinião, claro - os grandes críticos do século XX, os julgamentos-chave, os mais interessantes, verá que têm ligação com o marxismo. Não são diretamente marxistas, ligados à militância política, mas são próximos. O marxismo autodenominado e de escola é, em geral, medíocre. Isso tudo é efeito do stalinismo. Criou-se uma espécie de maldição. Seja como for, passado o tempo, a crítica sem referência social e dialética sai bem diminuída da comparação com Adorno, Benjamin, com o "bom" Lukács, com Auerbach. Aliás, o lado esquerdo de Auerbach foi pouco visto e ainda está por ser explicitado. Moretti foi examinar os papéis dele em Istambul, do tempo da guerra, que ele passou lá, e descobriu que na primeira versão o subtítulo de Mimesis era $A$ dialética da representação na literatura do Ocidente, e não A representação da realidade na literatura do Ocidente, como ficou na versão definitiva. ${ }^{25}$ Pode-se imaginar que depois da guerra, 
quando Auerbach resolve imigrar para os Estados Unidos, com o macartismo começando, ele tenha tirado a dialética do título. . . O fato é que o marxismo foi muito fecundo também fora de seus âmbitos imediatos.

André Botelho - Olhando hoje para Ao vencedor as batatas, pensamos em termos de um programa crítico-sociológico. O senhor mesmo já havia comentado noutras oportunidades e adiantou aqui também como o seu plano original já envolvia o que depois veio a ser Um mestre na periferia do capitalismo. Uma questão sociológica que me chama muito a atenção nesse desenvolvimento diz respeito à ambivalência ideológico-moral entre ideário burguês e paternalismo, inscrita na conduta dos grupos sociais, questão que, embora já estivesse presente nos primeiros romances, ganha destaque na "segunda fase" de Machado de Assis.

Roberto Schwarz - Em Iaiá Garcia, que é o romance da transição, a riqueza de análise social já é muito grande. A fenomenologia das relações de favor é impressionante. Procurei acompanhar analiticamente e descrever uma por uma - a acuidade e a sistematicidade do procedimento machadiano surpreendem a todo o momento. Dito isso, tratase do universo intuitivo da reflexão social brasileira, do qual as construções sociológicas correntes dão conta. O leitor de Gilberto Freyre, Sergio Buarque de Holanda e Caio Prado Jr. está em casa. Já com a segunda fase não é assim. Os termos do primeiro são complacentes demais, e os outros dois são demasiado progressistas para a configuração machadiana. O ceticismo ilustrado, sobretudo a compactação formal operada por Machado, que tornou tangível a complementaridade, ou melhor, a sincronia distante entre o padrão burguês ideal, o ângulo corrente dos países centrais e a nossa acomodação do escravismo liberal-paternalista, de excolônia, são de outra ordem. Esse é um mix que requer uma sociologia nova, que não está disponível, para a qual a crítica literária seria um indicadorchave. Como fica Dona Plácida, uma triste agregada, refletida nas prerrogativas descaradas de um proprietário à brasileira, refletidas na dicção breve e lúcida da análise setecentista e metropolitana do interesse individual, refletida na elegância autocomplacente da Belle Époque? Machado achou um modo, por meio da composição e da dicção característi- cas, de ativar esses espelhamentos interclasse, transatlânticos, entre matéria datada e estilo com outra data - mais a problemática moral e o sistema de diferenças do caso. Ele realmente rompeu as nossas limitações mentais correntes.

Lilia Schwarcz - O que é bonito também é o outro lado, não é? Ou seja, a comparação com o outro também leva à nossa própria estranheza. Como o senhor diz no começo de seu livro, na sua tão famosa quanto polêmica introdução, "toda reprodução é sempre uma apropriação". O que o seu trabalho mostrava também é a possibilidade de se pensar dos dois lados. A tensão também é relevante nos dois lados. A apropriação também é um deslocamento.

Roberto Schwarz - Claro.

André Botelho - Pensando nos procedimentos estéticos da obra de Machado de Assis, lembro de um artigo recente no qual o senhor chama a atenção para o fato de que, ironicamente, a atual consagração internacional de Machado, sobretudo nos círculos universitários norte-americanos, parece estar implicando na sua descontextualização históricosociológica. ${ }^{26}$

Roberto Schwarz- Quero continuar este ensaio, para apontar o jogo de poder mundial atrás das interpretações. Uma, que leva em conta a história local e que diz que Machado é um grande autor porque soube se ligar profundamente à vida social do país. A outra, a qual desconhece a mesma história, mas também acha que ele é um grande autor, dá outras razões. Machado é grande porque é uma variante uma diferença - no cânon dos grandes autores internacionais. Uma interpretação ancora o valor de Machado na experiência local, e a outra, no sistema de diferenças composto pelos clássicos da literatura universal. As abordagens, tão opostas, são complementares em certa medida, que é interessante explorar. São leituras separadas, que por momentos vão estar em guerra, porque uma vai reivindicar contra a outra. A inclusão de Machado na família dos grandes autores, onde ele tem posição própria, obviamente é um ganho. A linha interpretativa oposta dirá, na minha opinião, que é a história local que produz as peculiaridades que fazem diferença no sistema do cânon mundial. Peculiaridades que podem ser reconhecidas e valorizadas, 
mas não explicadas, sem referência à mesma história local. Num caso ficamos com a tradição das grandes obras e do diálogo dos gênios isolados; no outro, com uma história local de luta pela desprovincianização artística e pelo reconhecimento mundial. Tudo está em explicitar a parte de verdade em cada posição, em especial na restrição que uma faz à outra.

Lília Schwarcz - Uma história de formas reais, que são reiteradas no campo literário.

Roberto Schwarz - Exatamente, desde que essa reiteração de formas não seja entendida de maneira realista estreita.

Lília Schwarcz - Talvez o único outro autor brasileiro - você me corrija - que tenha recebido esse estatuto de autor brasileiro no exterior é Jorge Amado. Ao menos na França. Mas a recepção dele no exterior me parece que é em tudo diferente do que o que você apontava nos romances mais recentes de Machado de Assis.

Roberto Schwarz - Jorge Amado, até onde sei, não teve uma consagração artística importante. Ou melhor, teve a consagração da máquina do Realismo Socialista, que esteticamente era regressiva.

Lília Schwarcz - Ou então, é a consagração de um determinado Brasil, que se cria apenas para o exterior. Em tudo oposto ao de Machado.

Roberto Schwarz - Quem tem uma carreira internacional importante hoje, ligada ao feminismo, é Clarice Lispector. Mas eu não conheço o suficiente para palpitar.

André Botelho - Pensando agora em Duas meninas, os dois ensaios que compõem o livro, em parte talvez pela própria matéria de cada um deles, parecem apresentar respostas distintas à relação entre decadência econômica e fechamento da consciência social: em Dom Casmurro, Capitu é derrotada pelo sistema patriarcal em decadência; no caso do diário de Helena Morley, o senhor chama a atenção para o fato de a decadência econômica de Minas Gerais ter criado, ao contrário de um fechamento do mundo, uma abertura. Então, você tem a prosa desataviada do diário, uma menina iluminista... ${ }^{27}$
Roberto Schwarz - Capitu é derrotada. Mas o romance não é derrotado.

André Botelho - Correto, mas como o senhor pensa a questão em relação à Minha vida de menina? Lembro que, em geral, na literatura sociológica brasileira é comum entender que a decadência econômica leva a um fechamento da consciência social...

Lília Schwarcz-E não a um campo de possibilidades.

Roberto Schwarz - O diário dela de fato tem um lado um pouco milagroso. Aconteceu uma coisa na contracorrente, inesperada, que foi um fechamento com abertura. Não sou conhecedor da história de Minas, mas os entendidos falam de Diamantina como de algo extraprograma - Drummond, por exemplo, na boa crônica que dedicou a Minha vida de menina... Por algumas razões, que agora não saberia resumir, a decadência econômica e urbana lá veio acompanhada de luzes mentais e alegria, e de certa atenuação dos antagonismos sociais. Drummond fala da cidade "chupista", em que se bebia vinho e onde a decadência do ouro não se tornou lúgubre. Foi uma cidade festeira, essas coisas existem. Voltando ao livro, além das surpresas de Diamantina houve o milagre de uma menina precoce, que se pôs a observar e a escrever antes de estar interessada em namorar e casar, capaz de bastante inconformismo, engraçada, um pouco protestante, entusiasta das cerimônias católicas, agudamente consciente de suas contradições etc. São várias as razões que fizeram de seu diário uma coisa luminosa. Se ela continuasse a escrever, é provável que não fosse interessante daquele jeito depois. O momento histórico privilegiado, beneficiado por certa indefinição, logo depois da Abolição e um pouco antes do trabalho assalariado propriamente dito, um lugar alegre, a menina genial na idade certa, uma conjunção irrepetível. Todo mundo conhece meninas geniais, só que...

Lília Schwarcz - Elas crescem...

Roberto Schwarz - Os cadernos - que foram dar no livro - aconteceram só porque o pai, seguindo uma moda européia, mandou-a escrever um diário. Ela pegou o jeito, gostou, foi aplaudida e se desenvolveu. O conjunto é de uma complexidade e ressonância interna - as correspondências incríveis entre as anedotas - próprias da grande literatura, sem pre- 
juízo da singeleza. Já que estamos falando da sua qualidade literária, não custa notar que ela é - até onde vejo - superior a quase tudo na literatura brasileira do tempo. Essa opinião pareceu exagerada a vários colegas de Letras, porque acham que os cadernos de uma garota, mesmo engraçada, não devem ser comparados ao trabalhos de autores ilustres. Sob esse aspecto, o diário de Helena Morley forma par com o Sargento de milícias, um livro que também não tem a pompa da grande obra. A forma e a sua qualidade são objetivas, independentemente da intenção e da pretensão do autor. Helena sequer sabia que estava escrevendo um livro, mas a qualidade, o sistema denso e variado das relações internas, está lá. O que importa é o que foi organizado e escrito. Nós, os críticos, todos ilustrados e modernos, em princípio sabemos que a forma é objetiva, que a intenção do autor não é o que conta, gostamos de falar da mort de l'auteur etc., mas no frigir dos ovos, no dia-a-dia da avaliação, os bons continuam os de sempre. Vocês leiam os consagrados da época - com a exceção de Machado - e comparem com o diário. Esteticamente, não há comparação. Mostrem Minha vida a um estrangeiro e ele imediatamente vai dizer que é genial. Mostrem os contemporâneos consagrados, e ele vai dizer que um é interessante, o outro precursor. Mas genial? O livro de Morley é feliz como as grandes obras de arte, essa é que é a verdade, a meu ver. Mas o principal não está aí. É que a superioridade estética nalgum nível traduz um acerto da atitude extra-estética. A menina situava-se melhor diante da matéria brasileira do que os literatos calejados, com que é boa idéia compará-la.

\section{André Botelho - Sem intenção estética!}

Lília Schwarcz - É o que os professores não engolem. Penso que assimilam como documento de época, como repertório cultural, repertório de época. Mas na prática: "Esse livro não passa de um diário e diário não é literatura, segundo essa visão".

Roberto Schwarz - Tudo está em dissociar complexidade ou alcance objetivos da intenção autoral. O objet trouvé é central para a arte moderna, e para a crítica moderna Ele está lá, é uma coisa extraordinária, que, entretanto, não foi feita com essa intenção. E claro que a autora do diário, que já era adulta quando publicou os cadernos da menina, achou que aquilo tinha graça. Mas não terá pensado que fosse um grande livro. Já os literatos amigos do marido, quando o livro saiu, foram prontos no reconhecimento. Gilberto Freyre, Manuel Bandeira, Rubem Braga, Carlos Drummond, Elizabeth Bishop - um batalhão respeitável - todos disseram que era extraordinário. Georges Bernanos mandou uma cartinha: "A senhora escreveu um livro genial". Depois virou um presente para mocinhas e aí ficou.

Lília Schwarč- Impressionante. A última pergunta é só uma curiosidade - eu acho que o senhor já adiantou um pouquinho. Quais são os novos projetos, os projetos em pauta?

Roberto Schwarz - Vou desenvolver o ensaio sobre a leitura nacional e internacional de Machado.

\section{Notas}

1 Além da realização desta entrevista, o GT "Pensamento Social no Brasil" também organizou, no âmbito do referido Encontro, a mesa redonda "Ao vencedor as batatas 30 anos: crítica da cultura e processo social", coordenada por André Botelho, que contou com as participações de Sergio Miceli, Heloisa Starling e, pela primeira vez na Anpocs, do próprio Roberto Schwarz.

2 Ao vencedor as batatas: forma literária e processo social nos inícios do romance brasileiro, São Paulo, Duas Cidades, 1977.

3 "Dialética da malandragem" analisa Memórias de um Sargento de Milícias, de Manuel Antonio de Almeida, originalmente publicado como folhetim no suplemento "A Pacotilha" do Correio Mercantil de junho de 1852 a julho de 1853. O ensaio de Antonio Candido foi publicado originalmente em 1970 no número 8 da Revista do Instituto de Estudos Brasileiros e republicado em $O$ discurso e a cidade (São Paulo, Duas Cidades, 1993).

4 Roberto Schwarz refere-se a Um mestre na periferia do capitalismo: Machado de Assis (São Paulo, Duas Cidades, 1990).

5 Fernando Henrique Cardoso: Capitalismo e escravidão no Brasil meridional, São Paulo, Difusão Européia do Livro, 1962.

6 Maria Sylvia de Carvalho Franco, Homens livres na ordem escravocrata, São Paulo, IEB/USP, 1969.

7 O ensaio "As idéias fora do lugar", posteriormente reunido em Ao vencedor as batatas (1977), foi originalmente publicado no número 3 de Estudos (Cebrap, São Paulo, 1973). 
8 Antonio Candido, "De cortiço a cortiço", Novos Estudos-Cebrap, São Paulo, n. 30, 1991 - reunido posteriormente em $O$ discurso e a cidade, op. cit.

9 "A importação do romance e suas contradições em Alencar", em Ao vencedor as batatas, op. cit.

10 Referência a Um mestre na periferia do capitalismo: $M a$ chado de Assis, op. cit.

11 Michael Baxandall, Padrões de intenção, São Paulo, Companhia das Letras, 2006.

12 Referência a Um mestre na periferia do capitalismo, op. cit., e a "Nacional por subtração", aula dada no curso "Tradição/Contradição" da Funarte, publicada na Folha de São Paulo em 7 de junho de 1986 e posteriormente em Que horas são? Ensaios (São Paulo, Companhia das Letras, 1987).

13 Referência ao artigo "As idéias estão em seu lugar", de Maria Sylvia de Carvalho Franco publicado no número 1 de Cadernos de Debate, 1976.

14 Paulo Arantes, Sentimento de dialética na experiência intelectual brasileira: dialética e dualidade segundo Antonio Candido e Roberto Schwarz, Rio de Janeiro, Paz e Terra, 1992.

15 Referência especialmente a Fernando Henrique Cardoso e Enzo Faletto, Dependência e desenvolvimento na América Latina: ensaio de interpretação sociológica (México, Siglo XXI, 1969 [ver 3 ed., Rio de Janeiro, Zahar Editores, 1975]), livro escrito entre os anos de 1967 e 1968, quando os autores participavam da Comissão Econômica para América Latina e Caribe - Cepal; e a Fernando Henrique Cardoso, O modelo político brasileiro (São Paulo, Difel, 1973).

16 Joaquim Nabuco, O Abolicionismo [1884], 5 ed., Petrópolis, Vozes, 1988.

17 Referência a Formação do Brasil contemporâneo [1942], São Paulo, Brasiliense, 1989.

18 Referências a Alfredo Bosi, "A escravidão entre os dois liberalismos", em Dialética da colonização (São Paulo, Companhia das Letras, 1992), e a Carlos Nelson Coutinho, "Cultura brasileira: um intimismo deslocado, à sombra do poder?" (Cadernos de Debate, n. 1, 1976).

19 Franco Moretti, Atlas do romance europeu, 1800-1900, trad. de Sandra Guardini Vasconcelos, São Paulo, Boitempo, 2003; e, especialmente, "Conjecture on world literature”, New Left Review, 1, January-February, 2000, pp. 54-68; "More conjectures", New Left Review 20, March-April, 2003, pp. 73-81; e "The end of the beginning”, New Left Review, 41, September-October, 2006, pp. 71-86.

20 Roberto Schwarz, Misplaced ideas: essays on Brazilian culture, Londres/NovaYork, Verso, 1992.

21 Rodrigo Naves, A forma difícil: ensaios sobre arte brasileira, São Paulo, Ática, 1990.

22 Referência a Antonio Candido, Formação da literatura brasileira, São Paulo, Martins, 1969.
23 Referência especialmente a Roberto Schwarz, "Sobre a Formação da literatura brasileira" e "Os sete fôlegos de um livro", em Seqüencias brasileiras: ensaios, São Paulo, Companhia das Letras, 1999.

24 Referência à análise de Schwarz do método crítico de Antonio Candido desenvolvida em "Adequação nacional e originalidade crítica", em Seqüências brasileiras, op. cit.

25 Erich Auerbach, Mimesis: a representação da realidade na literatura ocidental, 4 ed., São Paulo, Perspectiva, 1998.

26 Roberto Schwarz, "Leituras em competição", Novos estudos - Cebrap, n. 75, 2006.

27 Referências a Machado de Assis, Dom Casmurro [1899], em Obra Completa, Rio de Janeiro, Aguilar, 1962; e a Helena Morley, Minha vida de menina, Rio de Janeiro, José Olympio, 1942. 


\section{AO VENCEDOR AS BATATAS 30 ANOS: CRÍTICA DA CULTURA E PROCESSO SOCIAL: ENTREVISTA COM ROBERTO SCHWARZ}

\section{Por Lília Schwarcz e André Botelho}

Palavras-chave: Ao vencedor as batatas; Experiência social brasileira; Crítica da cultura; Forma Estética.

Roberto Schwarz concedeu esta entrevista em 24 de agosto de 2007, em sua casa em São Paulo, e que integrou as atividades elaboradas pelo Grupo de Trabalho Pensamento Social no Brasil para homenagear os trinta anos de Ao vencedor as batatas no âmbito do XXXI Encontro Anual da Anpocs. Ele fala sobre a formulação do livro, sua recepção ao longo desses anos e desenvolvimentos em trabalhos posteriores. Assim, entre outras questões cruciais, Schwarz revisa o debate sobre a dualidade inscrita na experiência social brasileira, seus efeitos na vida cultural e as diferentes respostas dadas a ela; reafirma o potencial heurístico da pesquisa da forma estética - não apenas dos "acertos estéticos", mas também dos "desacertos" - para a compreensão da vida social, bem como a importância da especificação do sentido histórico das formas e idéias no trabalho do crítico da cultura.
THE THIRTIETH ANNIVERSARY OF AO VENCEDOR AS BATATAS: A CRITIQUE ON CULTURE AND THE SOCIAL PROCESS. AN INTERVIEW WITH ROBERTO SCHWARZ

By Lília Schwarcz e André Botelho

Keywords: Ao vencedor as batatas; Brazilian social experience; Culture critic; Esthetic form.

This interview, given by Roberto Schwarz on August 24, 2007 at his house in São Paulo, has integrated the activities elaborated by the Grupo de Trabalho Pensamento Social (Social Thinking Workgroup) in Brazil to honor the thirtieth anniversary of Ao vencedor as batatas in the scope of the $31^{\text {st }}$ Anpocs Annual Meeting. It covers the conception of the book, its reception along the years, as well as developments in posterior studies. Thus, among other crucial questions, Schwarz revises the debate on the duality inscribed in the Brazilian social experience, its effects on the cultural life and the different responses given to it; it also reaffirms the heuristic potential of the research on the aesthetic form - not only the so-called "aesthetic hits" but also the "misses" towards the understanding of the social life, as well as the importance of specification in the historical meaning of the forms and ideas in the work of the culture critic.
AU VAINQUEUR LES POMMES DE TERRE 30 ANNÉES: CRITIQUE DE LA CULTURE ET PROCESSUS SOCIAL: INTERVIEW AVEC ROBERTO SCHWARZ

Par Lília Schwarcz et André Botelho

Palavras-chave: Ao vencedor as batatas; Expérience sociale brésilienne; Critique de la culture; Forme esthétique.

Roberto Schwarz nous a concédé cette interview le 24 août 2007 dans sa maison à São Paulo. Elle a fait partie des activités mises en place par le Groupe de Travail Pensée Sociale au Brésil pour rendre hommage au 30 ans de Au vainqueur les pommes de terre dans le cadre de la XXXI ${ }^{\text {ème }}$ Rencontre Annuelle de l'Anpocs. Il aborde la formulation du livre, sa réception tout au long de ces années et ses développements dans des travaux postérieurs. Ainsi, parmi d'autres questions cruciales, Schwarz révise le débat sur la dualité inscrite dans l'expérience sociale brésilienne, ses effets sur la vie culturelle et les différentes réponses qui lui sont données; il réaffirme le potentiel heuristique de la recherche de la forme esthétique - non seulement des "ajustements esthétiques", mais aussi des "erreurs" - pour la compréhension de la vie sociale, ainsi que l'importance de la spécification du sens historique des formes et des idées dans le travail du critique de la culture. 